\title{
A ESPECTROMETRIA DE MASSAS APLICADA NA CLASSIFICAÇÃO E IDENTIFICAÇÃO DE MICROORGANISMOS
}

\begin{abstract}
Diego Magno ASSIS ${ }^{1^{*}}$
Luiz JULIANO ${ }^{2}$

Maria Aparecida JULIANO ${ }^{2}$

${ }^{1}$ Departamento de Biofísica, Universidade Federal de São Paulo, São Paulo, SP, Brasil / Faculdade de Mauá, Mauá, SP, Brasil.

${ }^{2}$ Departamento de Biofísica, Universidade Federal de São Paulo, São Paulo, SP, Brasil

*Autor correspondente - Email: diegofarmacia@yahoo.com.br - Fone: +55 (11) 55764450

RESUMO: A espectrometria de massas tem cada vez mais se tornado uma importante ferramenta analítica dentro da biologia. Nos últimos anos, essa ferramenta tem sido utilizada na identificação e classificação de microorganismos. Neste trabalho, nós mostramos como a espectrometria de massas é aplicada na microbiologia através dos princípios teóricos, da metodologia e as vantagens e desvantagens da técnica.
\end{abstract}

Palavras chave: identificação de microorganismos, espectrometria de massas

ABSTRACT: Mass spectrometry has become an important analytical tool in biology. Recently, this tool has been used in classification and identification of microorganisms. In this paper, we show how the mass spectrometry is applied to the microbiology through theoretical principles, methodology, advantages and difficulties.

Keywords: identification of microorganisms, mass spectrometry 


\section{O Encontro da Microbiologia com a Espectrometria de Massas}

Os seres humanos, animais e plantas estão e sempre estiveram em contato com os microorganismos. Essa relação e a possibilidade da existência de entidades vivas invisíveis ao olho humano sendo a causa de doenças infecciosas são suspeitas desde a Antiguidade. Os microorganismos eram uma preocupação ao homem devido a suspeita de serem os causadores de doenças contagiosas, putrefação de alimentos, bebidas, intoxicações e devastações de plantações. Em virtude desta preocupação, a história da microbiologia teve seus primeiros relatos já por volta de 1546 com Girolamo Fracastorius com a publicação do livro "de contagione et contagionis" em uma época em que se acreditava que as doenças eram consideradas castigo divino (FRACASTORIUS, 1546). Essa mentalidade perdurou até que foram realizadas as primeiras observações de "micróbios" por Robert Hooke e Antoni van Leewenhoek em meados dos 1680. A partir desta época, a microbiologia continuou a evoluir, porém muito lentamente em relação às outras ciências biológicas passando pelos experimentos com varíola realizados por Edward Jenner por volta de 1796 e chegando a meados do século XIX. Neste momento, a microbiologia começou a apresentar um verdadeiro avanço devido ao desenvolvimento de microscópios de alta qualidade juntamente com técnicas de esterilização, cultivo de microorganismos e técnicas citológicas. Nessa época é que surgiram grandes nomes da Microbiologia como o francês Louis Pasteur e o alemão Robert Koch (PELCZAR et al., 1996). Deste momento em diante, a Microbiologia deixou de ser meramente descritiva e começou a se desenvolver nas mais diversas áreas científicas fazendo a história da microbiologia nos últimos 160 anos ser repleta de acontecimentos marcantes com o envolvimento de grandes pesquisadores (http://www.microbeworld.org). Ambas as descobertas nos auxiliam até os dias atuais no diagnóstico, tratamento e prevenção de doenças relacionadas aos microorganismos, seja na área humana ou veterinária, seja na prospecção de microorganismos com aplicações no ramo alimentício, ambiental ou industrial. Em conjunto, essas descobertas são a base de todas as técnicas de identificação que são utilizadas até o momento e também a referência para que demais pesquisadores prossigam no desenvolvimento de novas técnicas e 
resultados que possam esclarecer questões ainda não respondidas. Sobretudo, questões que possam ser aplicadas e úteis à toda população mundial.

Para esclarecer algum fato ou aplicação cujo ocorra o envolvimento de microorganismos, primeiro é necessário conhecê-lo ou pelo menos classificá-lo. Em princípio, as técnicas para a classificação e identificação de microorganismos devem seguir alguns aspectos gerais tais como uma capacidade de identificação universal, ter um baixo custo de operação, apresentar um rápido processo de transferência de informações, propiciar o compartilhamento das informações através de bancos de dados que devem ser acessíveis e passíveis de atualizações regularmente e possibilitar a identificação de diferentes fontes.

Uma variedade de procedimentos laboratoriais satisfaz as condições mencionadas acima e pode ser utilizada na classificação taxonômica e na identificação de bactérias. Em laboratórios clínicos, estes métodos englobam a análise morfológica das colônias, coloração de Gram, exame microscópico e vários testes bioquímicos e fisiológicos, sejam eles manuais ou automatizados. No entanto, como tais testes bioquímicos dependem de processos metabólicos do microorganismo, o crescimento bacteriano e longos períodos de incubação são necessários e acabam sendo limitantes na liberação dos resultados. Além disso, muitas vezes estes resultados podem ser inconclusivos. Em adição a tais métodos, ainda pode-se utilizar de ferramentas de biologia molecular como a amplificação de determinados genes por PCR (reação em cadeia da polimerase), ensaios imunológicos como ELISA (enzyme linked imunosorbent assay), API (Analytical Profile Index), sequenciamento do RNA ribossomal da subunidade $16 \mathrm{~S}$ e marcadores fenotípicos. Porém, estas últimas técnicas são relativamente complicadas, de maior custo e não se adaptam bem à rotina e à demanda do número de amostras de laboratórios clínicos.

Atualmente, novas técnicas de identificação e classificação de microorganismos estão surgindo na tentativa de agilizar os resultados, diminuir os custos e chegar a identificações mais detalhadas que métodos convencionais ainda não respondem. Uma destas técnicas é a Espectrometria de Massas (EM), uma ferramenta já bastante utilizada pela física e pela química. A base teórica da EM já foi estabelecida ao longo de um século de estudos (BRIFFITH et al., 2008) e diferente da microbiologia, sua história é mais 
recente e muito mais resumida com somente alguns poucos nomes citados ao longo de sua trajetória. Os príncipios da espectrometria de massas surgiram com J.J Thomson (Nobel de Física - 1906) durante experimentos com a transmissão de eletricidade através de gases e o desvio de raios catódicos por campos eletromagnéticos (DAHAL, 1997). O primeiro espectrômetro de massas foi criado somente em 1922 por F. Aston (Nobel de Química 1922) e a técnica só ganhou maior dimensão devido à Segunda Guerra Mundial e ao Projeto Manhatan, na corrida pela obtenção de armas nucleares por enriquecimento de isótopos. Até por volta de 1940, os físicos dominaram a técnica tentando resolver questões de natureza fundamental do átomo. A partir deste período é que a ferramenta começou a ser utilizada na análise de moléculas orgânicas, tanto que em 1980, este tipo de análise já era uma rotina. Porém, a análise de moléculas de peso molecular mais elevado não era possível devido à decomposição dessas moléculas pelo forte processo de ionização.

A primeira tentativa na classificação de microorganismos foi realizada em 1975 (Anhalf, et al.,1975). No entanto, foi por volta dos anos 80 que técnicas mais brandas de ionização, como MALDI-TOF (matrix assisted lazer desorption/ionization - time of flight) e ESI (electronspray ionization), permitiram a análise de moléculas de peso molecular elevado a exemplo de proteínas, carboidratos e ácidos nucléicos sem a decomposição desses analitos (FENN, 2002; KARAS, 1985; TANAKA, 1988). Em consequência disto, a espectrometria de massas tornou-se uma ferramenta extremamente utilizada dentro da biologia em estudos de proteômica, caracterização de biomoléculas, entre outras. Nesse sentido, a EM começou a ser aplicada na microbiologia e como conseqüência, alguns trabalhos foram realizados na tentativa de obter espectros de massa de bactérias e assim classificar e identificar microorganismos (CLAYDON et al., 1996; DEMIREV et al., 1999; EDWARDS-JONES et al., 2000; FENSELAU et al., 2001; HETTICK et al., 2004; RUPF et al., 2005). Entretanto, nos últimos cinco anos é que a técnica tornou-se disponível para o uso na microbiologia deixando de ser domínio apenas de especialistas em espectrometria de massas.

\section{Princípios Teóricos da Espectrometria de Massas}


A espectrometria de massas é uma técnica utilizada no estudo das massas de átomos, moléculas ou fragmentos de moléculas. De uma forma geral, a espectrometria de massas baseia-se em propriedades físicas do analito de forma a determinar a relação entre a massa e a carga $(\mathrm{m} / \mathrm{z})$ de espécies ionizadas em fase gasosa (AEBERSOLD et al., 2003). Uma vez que a espectrometria de massas mede a relação entre massa e carga, um espectrômetro de massas engloba uma fonte de ionização para a obtenção de íons, um analisador de massas, o qual separa os íons formados, um detector desses íons e um sistema de aquisição dos dados. Em geral, as fontes de ionização mais comumente empregadas são ESI (Electronspray Ionization) e MALDI (Matrix Assisted Lazer Desorption Ionization) e os analizadores são os quadrupolos, íon-traps, time of flight (TOF), Fourier-transform ion cyclotron resonance (FT-ICR), orbitrap, entre outros (GLISH, et al., 2003). Atualmente, são comercialmente disponíveis dezenas de espectrômetros de massas com diversas combinações de fontes e analisadores distribuídos por várias empresas. No entanto, na idenficação e classificação de microorganismos, o que mais se tem utilizado são espectrômetros do tipo MALDI-TOF.

A tradução que mais esclarece a sigla MALDI seria processo de ionização por dessorção a laser assistida por matriz, ou seja, a matriz é um ácido orgânico (Figura 1) a qual fornece um próton para o processo de ionização da amostra. Ao mesmo tempo, tem a capacidade de absorver a energia emitida por um laser (light amplification stimulated energy radiation) e desencadear um processo de dessorção, o que possibilita a passagem da amostra em estado sólido para o estado gasoso. Já a sigla TOF (Time of Flight) caracteriza o tempo de vôo da amostra ionizada em um tubo de vácuo até que esta atinja o detector (TANAKA et al., 1988). Em resumo, uma vez ionizada e dessorvida, a amostra é acelerada por um campo elétrico dentro de um tubo de vácuo, separada em função da sua massa molecular e sua carga e assim, tem-se a medida da relação massa/carga (Figura 2). 
<smiles>COc1cc(/C=C/C(=O)O)cc(OC)c1O</smiles>

Figura 1: Estrutura química de duas matrizes comumente utilizadas. (A) ácido $\alpha$-ciano-cinamínico e (B) ácido sinapínico.

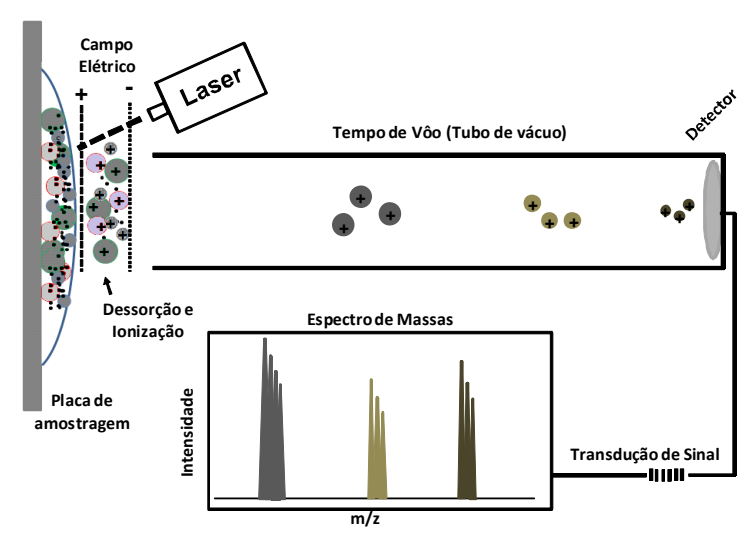

Figura 2: Figura esquemática de um espectrômetro de massas MALDI-TOF. A amostra é depositada sobre uma placa juntamente com a solução de matriz (círculos pretos menores) ocasionando a ionização da amostra. Em seguida, a placa é colocada no interior do equipamento onde fica alinhada com um tubo de vácuo. O laser dispara pulsos de luz que são absorvidos pela matriz provocando o processo de dessorção da matriz e da amostra. A amostra na fase gasosa e ionizada (representada por círculos com o símbolo +) é acelerada por um campo elétrico em um tubo de vácuo onde são separadas em função da relação massa/carga. O tempo (tempo de vôo) que a amostra leva para percorrer a distância entre a placa e o detector é proporcional à massa molecular, de forma que as moléculas menores chegam mais rápido ao detector. Há uma transdução de sinal e o espectro de massas é gerado de acordo com a massa das moléculas que estão presentes na amostra.

\section{A Espectrometria de Massas aplicada à Microbiologia}

Com os conceitos teóricos apresentados, qualquer amostra independente da origem, será submetida ao mesmo processo de ionização, separação e detecção por MALDI-TOF. A EM aplicada na identificação de microorganismos analisa a bactéria como uma mistura de biomoléculas como proteínas, carboidratos, lipídios, DNA, RNA, entre outros, as quais 
apresentam massas moleculares diferentes, ou seja, uma grande quantidade de moléculas é detectada simultaneamente. Essa mistura de moléculas vai gerar um espectro de massas que é característica de cada espécie. Desta forma, diferentes microorganismos apresentam diferentes espectros de massa (figura 3) e ainda, um mesmo microorganismo relativamente apresenta o mesmo perfil de espectro de massas independente da condição de cultivo.

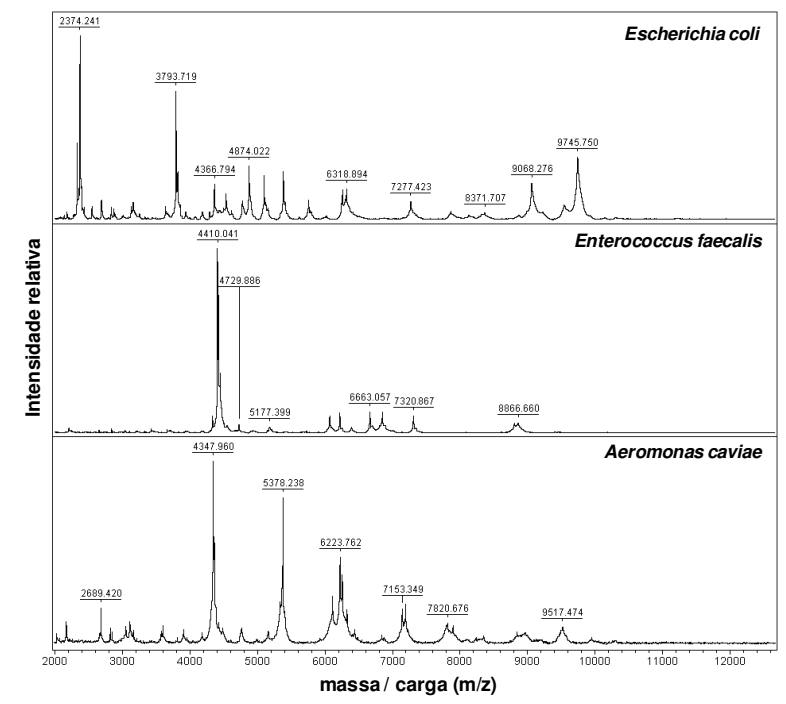

Figura 3: Espectro de massas de Escherichia coli, Enterococcus faecalis e Aeromonas caviae. O eixo x representa a relação massa/carga (daltons) das proteínas encontradas para os diferentes microorganismos e o eixo y representa intensidade relativa. Os números acima de cada pico representam a massa de cada proteína encontrada.

Diante destas características, empresas do ramo da espectrometria de massas montaram bancos de dados, que permanecem em constantes atualizações, contendo espectros de massas de bactérias (HETTICK et al; SHAW et al.; 2004). Um destes bancos é comercializado pela empresa Bruker Daltonics (Bremen, Alemanha) com o nome de BIOTYPER. Outro banco, nomeado SARAMIS é comercializado pela Shimadzu Corporation (Tóquio, Japão). A confiabilidade destes bancos já está comprovada por publicações de alto impacto que têm comparado a espectrometria de massas com outras ferramentas já utilizadas na identificação de microorganismos (CHERKAOUI et al., 2010; EIGNER et al., 2009; SENG et al.; 2009; VAN VEEN et al.; 2010). De um modo geral, estas publicações demonstraram que quando se comparou MALDI-TOF com provas bioquímicas automatizadas ou outros métodos, sejam em análises intra ou inter350 
laboratórios, a acurácia obtida foi entre 98 e 99\% para as espécies analisadas (SAUER et al.; Bizzini et al.; 2010).

\section{As vantagens e desvantagens da aplicação}

A utilização de MALDI-TOF é considerada revolucionária na identificação de microorganismos e uma das vantagens é a possibilidade de se utilizar células intactas de microorganismos que podem ser retiradas diretamente das colônias crescidas em placas de cultivo. A utilização de células intactas para espectrometria de massa (também designada ICM-MS, intact cell MALDI-TOF) produz um espectro de proteínas típicas de cada espécie, o que funciona como uma impressão digital ("fingerprinting"), que pode ser comparado aos espectros previamente identificados e depositados em banco de dados (CLAYDON et al., 1996; WALKER et al., 2002; VARGHA et al., 2006). O tempo de análise da amostra após o crescimento em placa é de cerca de 30 segundos enquanto que em outras metodologias esse tempo pode ser de horas e até dias. Sugerimos uma consulta à página http://www.bdal.com/MALDIBiotyper onde há um vídeo explicativo da tecnologia. Há ainda protocolos para a análise direta de urina e hemocultura sem prévio isolamento ou cultivo em outros meios acarretando um ganho de horas entre o diagnóstico e o início do tratamento.

Assim, MALDI-TOF tem apresentado grande aplicação em laboratórios de análises

clínicas tanto que já é amplamente utilizada em laboratórios clínicos da Europa e nos Estados Unidos, já está em processo de liberação pelo FDA (Food and Drug Administration). Certamente terá também aplicabilidade no âmbito ambiental, alimentício e industrial, ou seja, será útil a qualquer setor que exija controle microbiológico e que os resultados confiáveis sejam requeridos em curtos espaços de tempo (MARVIN et al., 2003; HSIEH et al., 2008). Esta metodologia apresenta inúmeras vantagens, como o baixo custo, necessita de quantidades muito pequenas de material biológico e pode ser aplicada em larga escala. Estudos de comparação mostraram que o custo, levando em conta material consumível, salários e depreciação do aparato em 5 anos, pode ser $25 \%$ quando comparado 
à outras metodologias e o custo de análise, sem considerar custo equipamento e mão de obra, sai na ordem de centavos (SENG et al., 2009; CHERKAOUI et al., 2010). Além dos ítens mencionados acima, os espectrômetros de massa necessitam somente de instalação elétrica e hoje, com as exigências ambientais e a sustentabilidade, não gera nenhum tipo de resíduo propiciando assim uma fácil implementação nos laboratórios.

Diferentemente de outras tecnologias nas quais os equipamentos são utilizados exclusivamente com uma finalidade, o espectrômetro de massas pode ser aproveitado para demais estudos nos quais algumas perguntas possam ser respondidas pela EM como proteômica, imagem por massa, seqüenciamento de proteínas, identificação de drogas e etc. Ainda, similarmente ao agrupamento em seqüenciamentos de $16 \mathrm{~S}$, o perfil protéico pode ser submetido a análises de "cluster" resultando na classificação taxonômica das diferentes espécies conforme o espectro de massa.

Uma das desvantagens desta tecnologia, é que a análise é dependente de bancos de dados que são disponíveis somente comercialmente e as entradas atuais são essencialmente de isolados clínicos o que não é agradável para quem para quem trabalha com isolados ambientais. No entanto, há a possibilidade da criação de bancos próprios com a variedade infinita de isolados sem a necessidade da licença destes bancos. Outra desvantagem é quanto a dificuldade de análise de microorganismos com parede espessa como no caso de alguns fungos filamentosos e micobactérias e por fim, quanto a testes de resistência, pois os resultados mostram qual o microorganismos, mas ainda não permitem obter o perfil de resistência aos antibióticos.

\section{O preparo da amostra}

Os métodos de identificação de microorganismos por espectrometria de massas descritos na literatura baseiam-se ou na detecção de peptídeos e proteínas, ou na detecção de ácidos nucléicos. Métodos na tentativa de se utilizar ácidos graxos ou açucares não se mostraram tão eficiente.

A metodologia em foco baseia-se no perfil de proteínas extraídas da bactéria inteira. 
No entanto, estudos já mostraram que a maioria das proteínas cujo sinal é detectado, é de origem ribossomal, mas podem eventualmente, aparecer proteínas que possivelmente estão presentes em maior abundância (RYZHOV et al., 2001). Diversas moléculas estão presentes na amostra e são analizadas pelo espectrômetro de massas, porém a quantidade de proteínas ribossomais é tão maior diante dos outros analitos, que estas acabam mascarando o sinal dos demais analitos. No caso de proteínas ribossomais, a abundância é explicada pelo número de ribossomos. Por exemplo, uma Escherichia coli em fase de duplicação pode apresentar cerca de 20.000 ribossomos o que reflete $25 \%$ do peso seco dessa bactéria, sendo que $65 \%$ do ribossomo é composto por RNA ribossomal e $35 \%$ por proteínas. A subunidade $30 \mathrm{~S}$ é composta por cerca de 21 proteínas e a subunidade $50 \mathrm{~S}$ por cerca de 34 proteínas. Essas proteínas são bastante conservadas geneticamente e tem como função, auxiliar na conformação tridimensional do ribossomo de forma que este exerça sua função (COOPER, 2002).

Para a determinação dos espectros, o organismo pode ser cultivado em diferentes meios de cultura (inespecífico, seletivo, rico, pobre, líquido, sólido) e o preparo da placa de MALDI-TOF pode ser realizado de duas formas: a primeira pela transferência direta de uma colônia da bactéria para uma placa de análise do equipamento e na segunda, por um processo de extração de proteínas através de um protocolo que utiliza etanol e ácido fórmico. Estas duas opções são as mais comumente utilizadas embora se tenha protocolos para algumas situações particulares como a formação de esporos (FREIWALD, et. al., 2009), análise direta de hemoculturas (LA SCOLA et al., 2009; PROD'HOM et al., 2010; STEVENSON et al., 2010) e de urina (BOROVSKAYA et al., 2009). Uma vez preparada a amostra, o espectro de massas é gerado de acordo com o perfil protéico da bactéria e este pode ser utilizado na identificação a nível de gênero, espécie e em alguns casos subespécies, comparando-o com perfis depositados em bancos de dados (Esquema 1). 


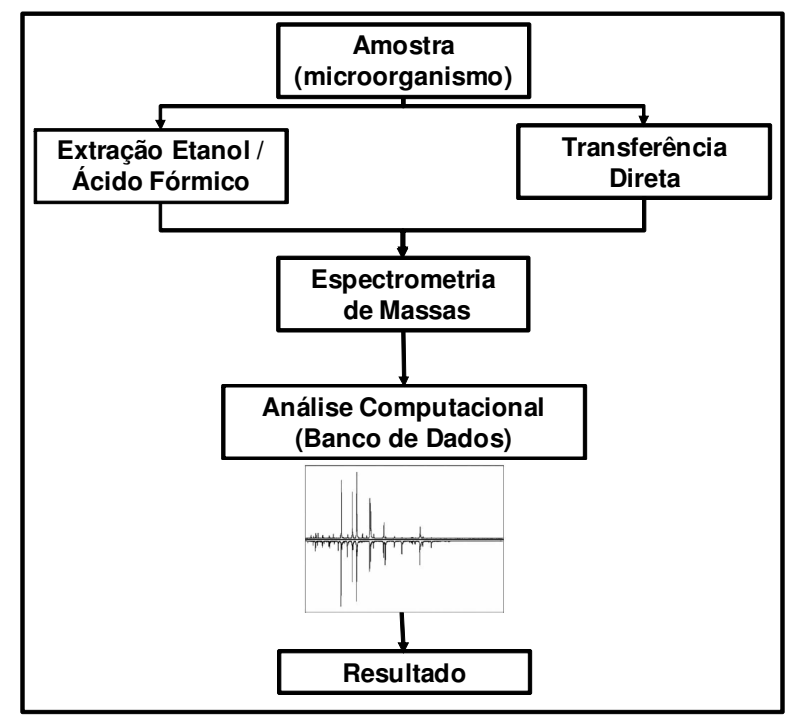

Esquema 1: Visão geral da metodologia empregada na identificação de microorganismos por espectrometria de massas.

\section{Considerações Finais}

A utilização da espectrometria de massas em laboratórios clínicos e de pesquisa em países europeus já é uma realidade. No Brasil, o primeiro espectrômetro de massas com esta aplicação foi instalado em 2010 e esta ferramenta já está sendo utilizada por alguns grupos de pesquisa (PASCON et al., 2011). Em laboratórios clínicos, a instalação desses equipamentos é somente uma questão de tempo devido à regulamentação da metodologia pela ANVISA. Para quem está envolvido no ensino de Microbiologia, aconselhamos a pensar em incluir este tópico nas disciplinas relativas ao tema na tentativa de já preparar os profissionais que irão se deparar com esta metodologia.

A técnica apresenta inúmeras vantagens e certamente se tornará a primeira escolha na identificação de microorganismos. Porém, ela não atuará sozinha necessitando ainda das ferramentas que os microbiologistas dispõem em seus laboratórios. Ainda, por mais confiável e rápida que seja a técnica, o aval final sempre será do microbiologista, o qual é insubstituível. Em adição, diante da agilidade dos resultados e da diminuição dos custos, sem dúvida quem mais se beneficia é o paciente, o qual depende do resultado e de 
melhorias na área microbiológica.

\section{Agradecimentos}

Os trabalhos pertinentes a este tema estão sendo financiados pela Fundação de Amparo a Pesquisa do Estado de São Paulo (FAPESP - 2009/52030) e Conselho Nacional de Pesquisa e Desenvolvimento (CNPq - processo 143319 / 2009-4).

\section{Referências}

AEBERSOLD, R.; MANN, M. Mass spectrometry-based proteomics. Nature. v. 42., p. 198-207, 2003.

ANHALT, J. P.; FENSELAU, C. Identification of bacteria using mass spectrometry. Anal. Chem., v. 47, p. 219-225, 1975.

BAN, N.; HANSEN, J.; MOORE, P.B.; Steitz, T. A. The Complete Atomic Structure of the Large Ribosomal Subunit at 2.4 Resolution. Science, v. 289., p. 905-920, 2000.

BIZZINI, A.; GREUB, G. Matrix-assisted laser desorption ionization time-of-flight mass spectrometry, a revolution in clinical microbial identification. Clinical Microbiology and Infection. v. 16., p. 1614-1619, 2010.

BOROVSKAYA et al., 19th ECCMID, 2009, Abstract P1065.

CHERKAOUI, A.; HIBBS, J.; EMONET, S. Comparison of two matrixassisted laser desorption ionization-time of flight mass spectrometry methods with conventional phenotypic identification for routine bacterial speciation. J Clin Microbiol., v. 48., p. 1169-1175, 2010.

CLAYDON, M. A.; DAVEY, S. N.; EDWARDS-JONES, V.; GORDON, D. B. The rapid identification of intact microorganisms using mass spectrometry. Nat. Biotechnol. v. 14., p. $1584-1586,1996$.

COOPER, G. M. A célula: uma abordagem molecular. 2. ed. Porto Alegre: Artmed, 2002.

DAHL, P. F. Flash of the Cathode Rays: A History of J. J. Thomson's Electron; Institute of Physics Publishing: Bristol, U.K., 1997. 
DEMIREV, P. A.; HOY, P.; RYZHOV, V.; FENSELAU, C. Microorganism identification by mass spectrometry and protein database searches. Anal Chem. v. 71., p. 2732-2738, 1999.

EDWARDS-JONES, V.; CLAYDON, M. A.; EVASON, D. J.; WALKER, J.; FOX, A. J.; GORDON, D. B. Rapid discrimination between methicillin-sensitive and methicillinresistant Staphylococcus aureus by intact cell mass spectrometry. J Med Microbiol., v. 49., p. 295-300, 2000.

EIGNER, U.; HOLFELDER, M.; OBERDORFER, K.; BETZ-WILD, U.; BERTSCH, D.; FAHR, A. M. Performance of a matrix-assisted laser desorption ionizationtime- of-flight mass spectrometry system for the identification of bacterial isolates in the clinical routine laboratory. Clin Lab., v. 55., p. 289-296, 2009.

FENN, J. B. Electrospray ionization mass spectrometry: How it all began. J. Biomol. Tech., v. 13., p. 101-118, 2002.

FENSELAU, C.; DEMIREV, P. A. Characterization of intact microorganisms by MALDI mass spectrometry. Mass Spectrom Rev., v. 20., p.157-171, 2001.

FRACASTOR, H. De Contagione et Contagiosis Morbis et Eorum Curatione.

(Originalmente publicado em Veneza, Itália em 1546., Wright WC, translator. New York, NY: G. P. Putnam's Sons, 1930.

FREIWALD, A.; SAUER, S. Phylogenetic classification and identification of bacteria by mass spectrometry. Nature Protocols., v.4., p. 732-742, 2009.

GLISH, G. L.; VACHET, R. W. The basics of mass spectrometry in the twenty-first century. Nature Reviews Drug Discovery., v. 2., p. 140-150, 2003.

GRIFFITHS J. A Brief History of Mass Spectrometry. Anal. Chem., v. 80., p. 5678-5683, 2008.

HETTICK, J. M.; KASHON, M. L.; SIMPSON, J. P.; SIEGEL, P. D.; MAZUREK, G. H.; WEISSMAN, D. N. Proteomic profiling of intact mycobacteria by matrixassisted laser desorption/ionization time-of-flight mass spectrometry. Anal Chem., v. 76., p. 5769-5776, 2004.

HSIEH, S. Y.; TSENG, C. L.; LEE, Y. S.; KUO, A. J.; SUN, C. F.; LIN, Y. H.; CHEN, J. K. Highly efficient classification and identification of human pathogenic bacteria by MALDI-TOF MS. Mol Cell Proteomics., v. 7., p. 448-456, 2008.

LA SCOLA, B.; RAOULT, D. Direct identification of bacteria in positive blood culture bottles by matrix-assisted laser desorption ionization time-of-flight mass spectrometry. PLoS ONE., v. 4., e804, 2009. 
KARAS, M.; BACHMANN, D.; HILLENKAMP, F. Influence of the wavelength in highirradiance ultraviolet laser desorption mass spectrometry of organic molecules. Anal Chem., v. 57., p. 2935-2939, 1985.

MARVIN, L. F.; ROBERTS, M. A.; FAY, L. B. Matrix-assisted laser desorption/ionization time of-flight mass spectrometry in clinical chemistry. Clin Chim Acta., v. 337., p. 11-21, 2003.

PASCON, R. C.; BERGAMO, R. F.; SPINELLI, R. X.; DE SOUZA, E. D.; ASSIS, D. M.; JULIANO, L.; VALLIM, M. A. Amylolytic microorganism from são paulo zoo composting: isolation, identification, and amylase production. Enzyme Res. 2011: 679624.

PELCZAR JR., J. M.; CHAN, E. C. S. \& KRIEG, N. R. Microbiologia: conceitos e aplicações., 2 ed. São Paulo: Makron Books, 1996.

PROD’HOM, G.; BIZZINI. A.; DURUSSEL, C.; BILLE, J.; GREUB, G. Matrix-assisted laser desorption ionization-time of flight mass spectrometry for direct bacterial identification from positive blood culture pellets. J Clin Microbiol., v. 48., p. 1481-1483, 2010 .

RUPF, S.; BREITUNG, K.; SCHELLENBERGER, W.; MERTE, K.; KNEIST, S.; ESCHRICH, K. Differentiation of mutans streptococci by intact cell matrix-assisted laser desorption/ionization time-of-flight mass spectrometry. Oral Microbiol Immunol., v. 20., p. 267-273, 2005.

RYZHOV, V.; FENSELAU, C. Characterization of the Protein Subset Desorbed by MALDI from Whole Bacterial Cells. Analytical Chemistry., v. 73., p. 746-750, 2001.

SAUER, S.; KLIEM, M. Mass spectrometry tools for the classification and identification of bacteria. Nature Reviews., v. 8., p. 74-82, 2010.

SENG, P.; DRANCOURT, M.; GOURIET, F. Ongoing revolution in bacteriology: routine identification of bacteria by matrix-assisted laser desorption ionization time-of-flight mass spectrometry. Clin Infect Dis., v. 49., p. 543-551, 2009.

SENG, P.; ROLAIN, J. M.; FOURNIER, P. E.; LA SCOLA, B.; DRANCOURT, M.; RAOULT, D. MALDI-TOF-mass spectrometry applications in clinical microbiology. Future Microbiology. v. 5, p. 1733-1754, 2010.

SHAW, E. I.; MOURA, H.; WOOLFITT, A. R.; OSPINA, M.; THOMPSON, H. A.; BARR, J. R. Identification of biomarkers of whole Coxiella burnetii phase I by MALDITOF mass spectrometry. Anal Chem. v. 76., p. 4017-4022, 2004.

STEVENSON, L. G.; DRAKE, S. K.; MURRAY, P. R. Rapid identification of bacteria in positive blood culture broths by matrix-assisted laser desorption ionization-time of flight mass spectrometry. J Clin Microbiol., v. 48., p. 444-447, 2010. 
TANAKA, K.; WAKI, H. 